\title{
Research on Psychological difficulties and Countermeasures Analysis of Poor Students at Vocational College
}

\author{
Wei Li jun ${ }^{1, a}$ \\ ${ }^{1}$ Luo he Medical College; Luo he, Henan Province 462000 \\ a email
}

Keywords: vocational poor students; mental health; influential factors; countermeasures

\begin{abstract}
This paper starts from poor students' psychological state of development of vocational colleges, production and analysis of poverty vocational students' mental health cause of the problem, and finally put forward practical countermeasures, hope to Higher Colleges of poor students psychological health education provided positive guidance.
\end{abstract}

\section{Psychological Dilemma Performance of Poor Students at Vocational Colleges}

(A) Psychological depression and anxiety

As poor students in higher vocational colleges, they are often shouldering the many pressures from the pressure the whole family and society, and some poor students in order to change the status quo, give yourself too much pressure is applied, these pressures and poor students incompatible development, will so that their physical and mental overdraft, combined with the pressure of the material aspects of life in the long run, some poor students demonstrated psychological characteristics of depression and anxiety, these mental health problems to a large extent affected the poor students in Higher learning institutions and life , and the learning and life affected exacerbated their mental anxiety, become a vicious cycle ${ }^{[1]}$.

(B) Sensitive and Inferiority

Most poor students from vocational schools in poor areas underdeveloped, these remote areas due to geographical location, economic development and literacy development is lagging behind, so that the students showed in life, learning, management and interpersonal aspects differences, these differences appear to increase the inferiority of poor students. Without economic strength of interpersonal conduct, poor students are retreated in interpersonal communication, xenophobic behavior. Over time, these poor students learning, and emotional aspects of life are in a passive state, so that they were more obvious inferiority.

(C) Self-enclosed mental

Poverty is a valuable asset in life, and many poor students can actively face the difficulties of life, and optimistic life. However, some poor students can't properly look at life of poverty that poverty is social injustice and make fun of fate, they complain, sensitive, suspicious, in the face of low life and predicament, more negative fall, do not know how to loved ones, teachers, friends for help, do not self-emotional catharsis, but in a closed state, the anguish buried inside the heart, this behavior makes these poor students from the group, self-enclosed.

(D) Interpersonal difficulties

Many poor students due to the poor family, childhood there is a strong psychological stronger, but because of poverty often exhibit feelings of inferiority. In interpersonal relationships, often afraid of being looked down and did not dare to open up with people, self-enclosed performance makes difficulties in interpersonal communication, I do not know how to communicate with people, do not dare others to help, this potential psychological performance so that they do not become conscious alternative exchanges, and more and more people around the discord, interpersonal difficulties ${ }^{[2]}$. 
(A) Pressure is generated by too high expectations

After fierce competition in the college entrance examination, many people have high expectations for the future, which is expected from the students as well as their families, when the college entrance examination scores are not very good, not admitted to their favorite universities, admitted to colleges, especially poor students, will feel a little frustrated that live up to the expectations of families, students, and that the neighbors look down on their own, for fear of their own great expectations sorry parents, With this mentality after entering college, give up on themselves, so that their can't always get rid of negative frustration bondage, had mental health problems ${ }^{[3]}$.

(B) Pressure from academic matters

For poor students, the "knowledge to change the fate of the" concept more firmly in the hearts of poor students tend to go to school to study as the only opportunity to get rid of fate, it is the best way to change the status quo, therefore, during college, poor students the studies will look very heavy, making this part of the poor students shouldered heavy pressure to learn more than the average for families with children. From poor mountain children out, carrying the family and more folks eyes, once a business school, will feel discredited in the face elders, over-emphasis on their studies so that they can't afford to fail in school, frustration is very strong, very prone to psychological problems.

(C) Pressure is generated by financial burden

For poor students in higher vocational colleges, the main problem stems from psychological factors too heavy economic burden. For the thousands of dollars per year higher vocational colleges tuition, ordinary families can afford onwards, and for poor students, the thousands of dollars the cost of living is almost a year of family income, and even years of savings, many poor families bear We can't afford the expensive cost of learning. In addition, poor students living expenses are short of money, families have overloaded the burden of student tuition fees, living expenses it is to save the province, the gap in consumption exacerbated by poor students' psychological problems.

(D) Enormous pressure of employment difficulties

Since the implementation of the national expansion policy, the number of graduates increase each year, millions of graduates go into the community. The country's employment is limited, it can't meet the employment needs of graduates, despite the employment pressure is the pressure of all college students have to face, but for poor students, the pressure is even greater. Poor students and families under great financial pressure to support a college student out if graduates do not find work, then certainly for the families as poor students worse. And today's employment environment is not very transparent, objective injustices still exist, some people with relationship through the back door, find a stable job, competition for jobs inequality makes poor students psychological conflict intensified, psychological and other extreme performance ${ }^{[4]}$.

\section{Effective Strategies of Poor Students' Psychological Harmony at Vocational College}

(A) Establish and improve the Poor Students in Higher Vocational Schools funding system

Many vocational colleges have the appropriate funding system for poor students, but a lot is a mere formality, it did not play a real role. Poor students to solve psychological problems fundamentally, it is important to provide them with financial assistance, and solve the worries of poor students, make it concentrate on their studies. First, higher vocational colleges should establish and improve the work-study system, through work-study system, poor students in obtaining financial resources, based on the culture of their own ability to ease the employment pressure will also help future; secondly, vocational College financial aid mechanisms should be built, with the help of school social support and preferential policies for poor students tuition deductible, and can help poor students complete their studies through student loans; again, vocational colleges can appropriately expand scholarship coverage, through the establishment of scholarships poor students to cultivate a strong fighting spirit and morale, but also to inspire students to form mental health.

(B) Offer psychological counsel for poor students in higher vocational colleges

Vocational College important means to solve psychological problems of poor students is mental 
health education, and give students positive guidance from the psychological aspect, so that out of the psychological errors. First, as a teacher and counselor vocational colleges depth visits to poor students live, giving them effective psychological support and help, give full play to the important role of teacher and counselor in the ideological and political education. Teacher and counselor poor students a better understanding of the living conditions and learning conditions, it is possible to know the students' psychological changes, role in helping poor students to get rid of psychological distress aspect can't be ignored; secondly, vocational colleges should offer psychological counseling agencies, Since counselors are more professional in terms of resolving psychological problems, in order to cater for poor students psychological problems to carry out targeted psychotherapy, which is incomparable teacher and counselor. Higher vocational colleges should provide students with more diverse psychological counseling and guidance support, such as the campus network, telephone, magazine, etc., help students to correct understanding of the problems, and actively courage to face the problem, not a negative fall mentality. In short, higher vocational colleges should adopt flexible ways to effectively improve the psychological problems of poor students ${ }^{[5]}$.

(C) Build the sound scientific education management strategies

In order to solve mental difficulties of poor student at vocational colleges, schools should give strong support in terms of policies and systems to give poor students more care and assistance so that they can feel the warmth and attention from the outside world, so as to establish a healthy attitude. On the economic front, higher vocational colleges to increase economic support for efforts to give more students to solve economic problems, so they can easily cope with difficult living conditions; in addition to economic support, schools should build a comprehensive education management system, construction healthy and harmonious atmosphere, the poor students in mental health issues into the context of ideological and political work and unremitting persist; Higher education institutions can establish a comprehensive network management system, enabling poor students to master specific information, it is possible more level, multi-angle poor students Education management to provide practical help and care, increase poor students psychological harmonious factors; in addition, vocational colleges can build poor students assessment mechanism to achieve pro-poor policies and student performance organic combination. To provide students more practice opportunities for poor students, they are under the premise of self-reliance, the ability to exercise their own, in order to better adapt to society.

\section{Conclusions}

In summary, as a special group of poor students in vocational colleges, it should receive special attention from the community, school and family. For poor students, in today's society and the education system continue to improve the external conditions favorable to a positive psychological adjustment, face difficulties in life that appears, continue to shape a positive and optimistic attitude towards life, enhance the ability to adapt to life, let yourself grow smoothly in the face of adversity, to create a healthy improvement in the plight of character, so as to make full use of the time available during the study, to learn more knowledge and skills for the community to make its due contribution.

\section{References}

[1] Weiliu, vocational Poor Students' Psychological Poverty "Cause Analysis and Countermeasures [J]. Guangxi Light Industry, 2011 (01).

[2] Wang mei Wu, Li haiyang. Situation and countermeasures Psychological Problems of Poor Students [J]. Guangxi Vocational and Technical College, 2011 (02).

[3] Huang GangWei. Maslow's hierarchy of needs and poverty reduction measures Universities Psychological Poverty [J] students. Southwest University for Nationalities (Humanities and Social Sciences), 2011(10). 
[4] Fan Lei. Poor students of higher vocational college "psychological poverty" performance and countermeasures [J]. Chinese business, 2010 (04).

[5] Ni Min, Yao Jie of vocational colleges Poor Students' Psychological Health Problems - Taking Suzhou College of Information Technology to investigate the carrier [J] SYSTEM AND SOCIETY, 2009 (32). 